\title{
THE FLUID SHIFT FROM THE VASCULAR COMPARTMENT IMMEDIATELY AFTER BIRTH
}

\author{
BY

\begin{abstract}
DOUGLAS GAIRDNER, JOHN MARKS, JANET D. ROSCOE and R. O. BRETTELL From the Cambridge Maternity Hospital
\end{abstract}

(RECEIVED FOR PUBLICATION MAY 20, 1958)

In an earlier paper (Gairdner, Marks and Roscoe, 1952) we drew attention to the fact that the haemoglobin $(\mathrm{Hb})$ level during the first day of life is generally much higher than at birth. We questioned the adequacy of the current explanation, that any rise in the $\mathrm{Hb}$ level after birth is the result of transfer of placental blood, and suggested that the effect merited study. We now present further observations comparing the composition of cord blood at birth with venous blood taken from a few minutes to a few hours after birth. Hb, packed cell volume, (PCV), plasma protein and plasma sodium have been measured. From these comparisons we conclude that after birth there is usually a shift of fluid, mainly whole plasma, from the circulation. The volume of the plasma shift may be large, amounting to an appreciable fraction of the initial plasma volume, and the effect may consequently prove to be of some clinical importance.

\section{Material}

Ninety-two infants were studied, of whom 73 were delivered vaginally and 19 by caesarean section. The mother's permission for blood sampling was obtained. Most of the subjects were normal, but a few of the mothers had toxaemia or diabetes; the results in these were similar to those of the normals and have not been separately analysed.

\section{Methods}

The cord was always clamped as soon as conveniently possible, both in vaginal and caesarean deliveries. A blood sample was taken by puncture of the umbilical vein between placenta and clamp. Subsequent specimens were taken from an external jugular, internal jugular or femoral vein, or from the ductus venosus (i.e. the continuation of the umbilical vein). The ductus venosus was used particularly for samples within a few minutes of birth. We have found that the ductus venosus can often be catheterized conveniently by inserting a widebore trocar into the terminal part of the umbilical vein in the cord, and threading a polythene catheter through it.
Samples were taken into heparinized tubes. $\mathrm{Hb}$ and PCV were estimated as described previously (Marks, Gairdner and Roscoe, 1955), $\mathrm{Hb}$ being estimated in duplicate in most cases. Plasma protein was estimated by the biuret method, using $0.2 \mathrm{ml}$. plasma. Plasma sodium was estimated by flame photometer. These four estimations required about $2.5 \mathrm{ml}$. of blood.

\section{Results}

(i) Change in Hb Level a Few Hours After Birth. In 92 infants samples were taken one to eight hours after birth and compared with cord blood. These included 19 caesarean deliveries, all but two of which were elective, and thus performed before the onset of labour. Results are shown in Fig. 1. Twenty-two cases showed a negligible change (less than $\pm 5 \%$ ) in $\mathrm{Hb}$ level after birth; in two cases there was a fall exceeding $5 \%$, while the remaining $68(74 \%$ of the sample) showed a rise exceeding $5 \%$. This rise amounted to $6-15 \%$ in 24 cases, to $16-25 \%$ in 23 cases, and to $26 \%$ or over in 21 cases. In five cases the rise exceeded $40 \%$, the most extreme example being that of an infant born with an abnormally low haemoglobin level of $10.5 \mathrm{~g} . / 100 \mathrm{ml}$. which six hours after birth had risen to $17.0 \mathrm{~g}$., a rise of $63 \%$. For the series as a whole the mean $\mathrm{Hb}$ levels were $16.6 \mathrm{~g} . / 100 \mathrm{ml}$. (S.D. 1.96) for cord blood and $19 \cdot 1 \mathrm{~g} . / 100 \mathrm{ml}$. (S.D. $2 \cdot 36$ ) at one to eight hours, giving a mean postnatal rise of $16 \%$. The figure of $16.6 \mathrm{~g}$. for cord blood $\mathrm{Hb}$ is not significantly different from $16.9 \mathrm{~g}$., the value found in our earlier series (Marks et al., 1955).

Since the means of the $\mathrm{Hb}$ rise (see Fig. 1) are as great at three hours as later (four to six hours), it seems that when the $\mathrm{Hb}$ level rises after birth the effect tends to be complete within three hours of birth, and perhaps in much less than this, judging from the few values available for one and two hours.

It will be seen from Fig. 1 that infants delivered by elective caesarean section showed the same order 


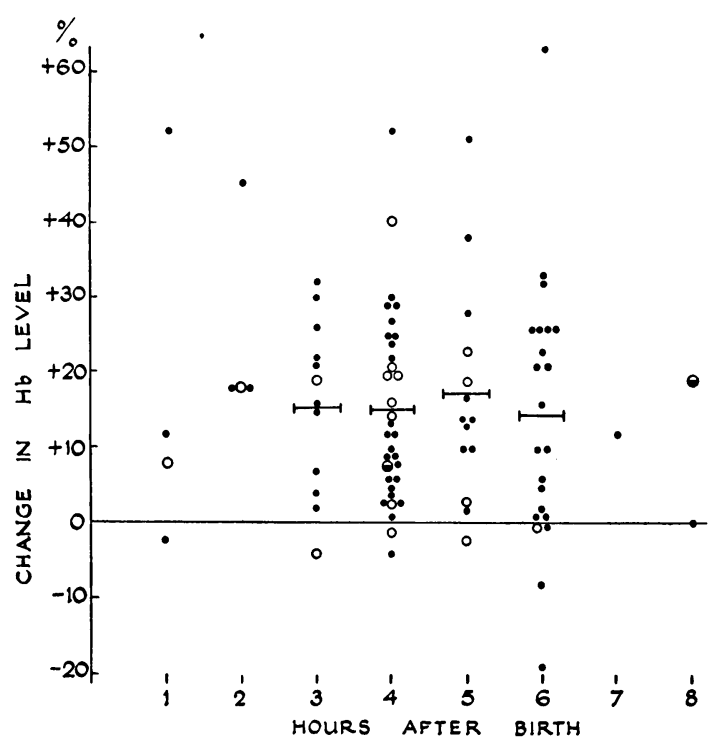

FIG. 1.-Change in $\mathrm{Hb}$ level in first few hours after birth. - 73 infants delivered vaginally.

- 17 infants delivered by elective caesarean section. - 2 infants delivered by non-elective caesarean section. Averages are shown for 3, 4, 5 and 6 hours.

of postnatal rise in $\mathrm{Hb}$ levels as did vaginally delivered infants, a crucial fact which bears on the part played by placental blood transfer in the postnatal $\mathrm{Hb}$ rise, to be discussed later.

(ii) Change in the Hb Level a Few Minutes After Birth. In order to determine how soon after birth the rise in $\mathrm{Hb}$ level begins, in 15 cases one or more venous samples were taken a few minutes after birth, either by means of a catheter introduced into the ductus venosus, or by puncture of another vein. Results are shown in Fig. 2. In seven cases the change in $\mathrm{Hb}$ level did not exceed $\pm 5 \%$; in one case there was a fall of $6.5 \%$; in the remaining seven cases there were rises of from $7 \%$ to $19 \%$. It will be noted that in both vaginal and elective caesarean deliveries the $\mathrm{Hb}$ level often showed a significant rise within a few minutes of birth. The rises within the first few minutes thus may approach those seen at a few hours and demonstrate that the changes can occur very rapidly after birth.

(iii) Uniformity of Samples from Different Veins. At this stage it was felt imperative to establish that the changes were real and did not merely reflect some difference in the composition of blood in different veins. In five infants, the youngest aged 20 minutes, samples were taken from more than one vein. Results (Table 1) show that in no subject did the $\mathrm{Hb}$ level vary by more than $0.3 \mathrm{~g} . / 100 \mathrm{ml}$. in different veins, a maximum variation of $1.5 \%$.

(iv) Change in Packed Cell Volume. In 39 cases the PCV was estimated in addition to the $\mathrm{Hb}$ level,

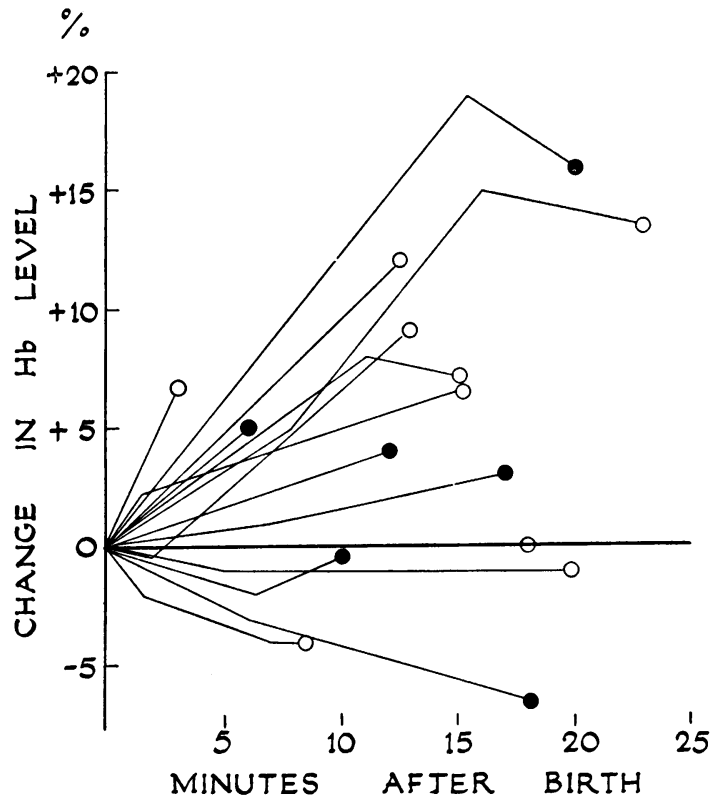

FIG. 2.-Change in $\mathrm{Hb}$ level in the first few minutes after birth. 6 infants delivered vaginally.

O 9 infants delivered by elective caesarean section.

TABLE 1

UNIFORMITY OF BLOOD SAMPLES FROM DIFFERENT VEINS

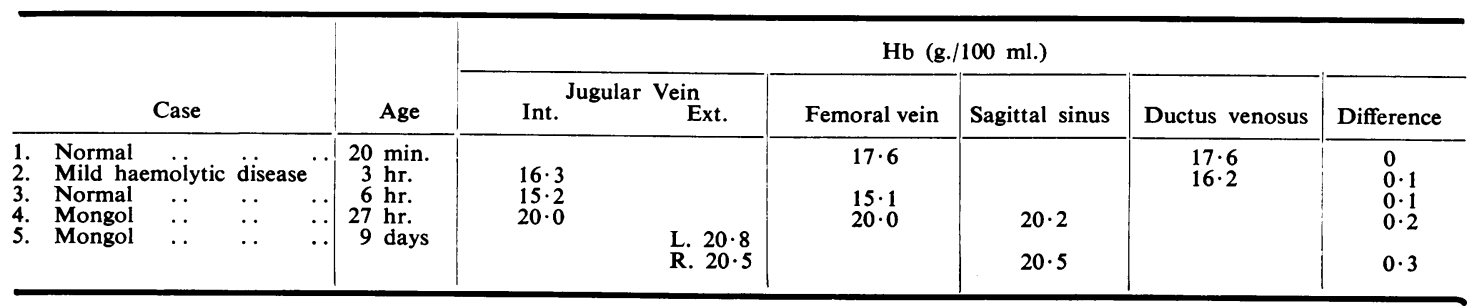




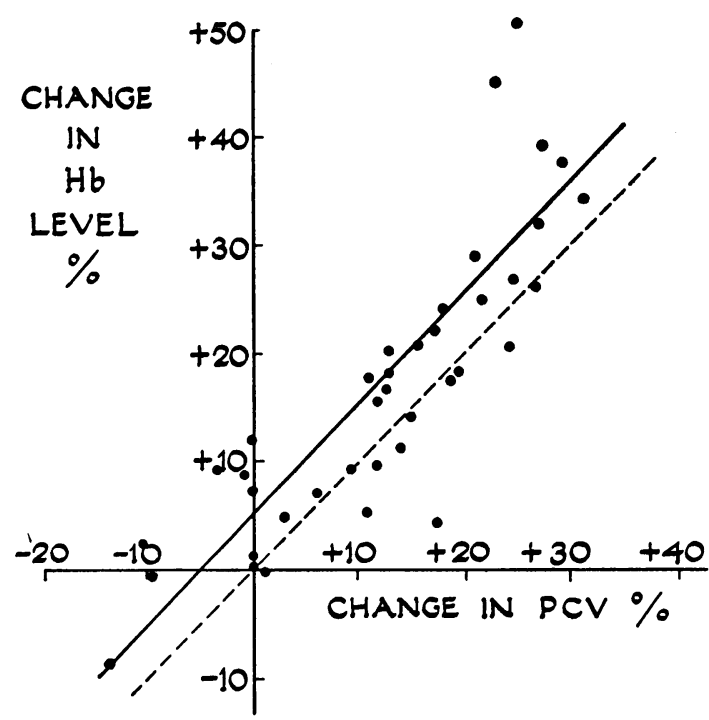

Fig. 3.-Relation of change in $\mathrm{Hb}$ level 1-8 hours after birth, to change in PCV, 39 cases. The broken line bisects the axes. Note that the change in $\mathrm{Hb}$ tends to exceed the change in PCV

and in Fig. 3 the percentage change in PCV is compared with the percentage change in $\mathrm{Hb}$ level. If the $\mathrm{Hb}$ and PCV had moved strictly in parallel, the points would have been grouped around the broken line shown; in fact the majority fall well above this line, i.e. the rise in $\mathrm{Hb}$ level is usually proportionately greater than the rise in PCV level. The calculated regression line is shown. In order to test the significance of this trend the percentage change in PCV was compared with the percentage change in $\mathrm{Hb}$ by the $\chi^{2}$ test. The difference was highly significant $\left(\chi^{2}=215 \cdot 9, \quad\right.$ d. of $f .=38$, $\mathrm{p}=<0.001$ ).

Since the ratio $\frac{\mathrm{Hb} \text { concentration }}{\mathrm{PC}} \overline{\mathrm{V}}$ defines the mean corpuscular $\mathrm{Hb}$ concentration (MCHC), these results are equivalent to stating that after birth there is a significant rise in MCHC. In a series of 21 cases* the mean MCHC of cord blood was $32 \cdot 3$ and in blood at one to eight hours $33 \cdot 6$, an increase of $4.0 \%$.

\footnotetext{
* It was discovered that one of the centrifuges used had been running at less than the prescribed 3,000 r.p.m. leading to incomplete packing of red cells and to incorrectly high PCV values. Therefore the 18 cases involved were excluded when calculating MCHC values, leaving the 21 cases quoted.

These 18 cases have not been excluded from the data for Fig. 3 for the following reason. Since the effect of incomplete packing is relatively greater in blood samples having a high PCV, the percentage increase in PCV after birth would tend to have been over-estimated. The point we have sought to demonstrate in Fig. 3 is that when, after birth, the $\mathrm{Hb}$ rises, the PCV tends to rise relatively less. The error under consideration would therefore tend to shift results in a direction opposite to that of the trend we are demonstrating.
}

(v) Change in Plasma Protein Concentration a Few Hours After Birth. Plasma protein was measured in 17 cases, care being taken to reject any sample showing haemolysis, to which blood samples in the early days of life are annoyingly prone. The protein concentration showed either a negligible change of less than $\pm 5 \%$ (six cases) or a small postnatal rise of from $6 \%$ to $20 \%$ (11 cases). The mean value for cord blood was $6.5 \mathrm{~g} . / 100 \mathrm{ml}$. and at one to eight hours was $7.0 \mathrm{~g}$., a mean postnatal rise of $7 \cdot 7 \%$.

(vi) Change in Plasma Sodium Concentration. This was measured in 14 cases. The mean value for cord blood was $145 \mathrm{mEq}$./1 and at one to eight hours was $146 \mathrm{mEq} . / 1$, a non-significant difference.

\section{Discussion}

To summarize the main findings, within a few hours of birth, there is frequently:

(1) A substantial rise in the $\mathrm{Hb}$ level, which reaches its maximum within three hours. In many cases this rise exceeds $25 \%$, and it may reach $50 \%$ or more. In some cases the rise exceeds $10 \%$ within 15 minutes of birth.

(2) A rise in $\mathrm{MCHC}$, averaging $4.0 \%$.

(3) A rise in plasma protein concentration of up to $20 \%$.

(4) No change in plasma sodium concentration.

Before considering the possible mechanisms responsible for these changes, it is essential to define certain terms used throughout the discussion and to relate them to each other.

In order to estimate the relative proportion of red cells in a sample of blood, we have centrifuged it in a Wintrobe tube for 30 minutes. The proportion of red cells thus determined is the packed cell volume (PCV). The PCV does not in fact represent the true volume of the red cells in the blood, since there is a small amount of trapped plasma in the red cell layer. Within the ranges of haematocrit and centrifugation applicable to this study, this can be allowed for by utilizing a factor of 0.95 (Chaplin and Mollison, 1952). The PCV thus corrected is the venous haematocrit. Thus, venous haematocrit $=0.95 \times \mathrm{PCV}$.

Blood in small vessels contains a greater proportion of plasma than does that in large vessels. Consequently the haematocrit of blood from a vessel such as a vein (venous haematocrit) is higher than the true body haematocrit. The ratio

$$
\frac{\text { body haematocrit }}{\text { venous haematocrit }}
$$

has been found to have a value of 0.91 in adults (Chaplin, Mollison and Vetter, 1953) and of 0.87 
in newborn infants a few hours old (Mollison, Veall and Cutbush, 1950). Thus for an infant after birth, body haematocrit $=0.87$ venous haematocrit

$$
\begin{aligned}
& =0.87 \times 0.95 \times \mathrm{PCV} \\
& =0.83 \times \mathrm{PCV} .
\end{aligned}
$$

The postnatal rise in the haemoglobin level might be brought about by one of three possible mechanisms:

(1) A redistribution of plasma within the vascular compartment.

(2) An addition to the red cell volume.

(3) A loss of plasma fluid.

(1) Redistribution of Plasma Within the Vascular Compartment. As has already been stated, the ratio $\frac{\text { body haematocrit }}{\text { venous haematocrit }}$ in newborn infants a few hours old has the value of $0 \cdot 87$. In the foetus before birth there is no direct evidence of such a difference between the haematocrit in different parts of the circulation. If we choose to suppose that in the foetus the distribution of red cells and plasma is uniform, after birth a redistribution of plasma would take place, with some of the plasma in effect pooling in the smaller vessels. Then, considering an infant where at birth the venous haematocrit is $h_{1}$, this will be identical with the body haematocrit, while after birth the venous haematocrit $h_{2}$ will be given by

$$
\mathrm{h}_{2}=\frac{\text { body haematocrit }}{0.87}=\frac{\mathrm{h}_{\mathrm{1}}}{0.87},
$$

from which the percentage rise in haematocrit after birth $100\left(\frac{h_{2}-h_{1}}{h_{1}}\right)$ can be calculated as $15 \%$.

Since PCV is proportional to venous haematocrit this figure of $15 \%$ would also be the percentage increase in PCV after birth.

Under these hypothetical conditions, then, redistribution of plasma within the vascular compartment could in theory cause the PCV to rise by as much as $15 \%$, but not more. However, rises greater than $15 \%$ are often observed (see Fig. 3).

While, therefore, we have no reason to believe that in foetal life the small vessels do contain less plasma relative to large vessels than is the case in the infant after birth, we cannot exclude this possibility. But if after birth some redistribution of plasma within the vascular compartment does occur, then it is clear on quantitative grounds that this can do no more than make some contribution to the large rise in PCV which is often observed.

(2) Addition to the Red Cell Volume. It will be convenient first to define the approximate size of the increase in red cell volume which would be necessary to produce the observed effect. This can be calculated in terms of the change in PCV for an average infant as follows.

We may take as a typical instance an infant of $3.4 \mathrm{~kg}$., with a PCV at birth of $53 \%$, rising by $15 \%$ after birth to $61 \%$, corresponding therefore to a body haematocrit of $44 \%$ at birth and $50.6 \%$ after birth. With a PCV of $61 \%$ the blood volume after birth, obtained from the data of Mollison, Veall and Cutbush (1950) can be estimated to be $90 \mathrm{ml} . / \mathrm{kg}$. or $306 \mathrm{ml}$. If it be assumed that $(a)$ the plasma volume remains the same after birth as before birth, then the composition of the circulating blood will be as shown in Fig. 4 (a), while if (b) the blood volume be assumed to remain constant, then the state of affairs after birth will be as in Fig. 4 (b).

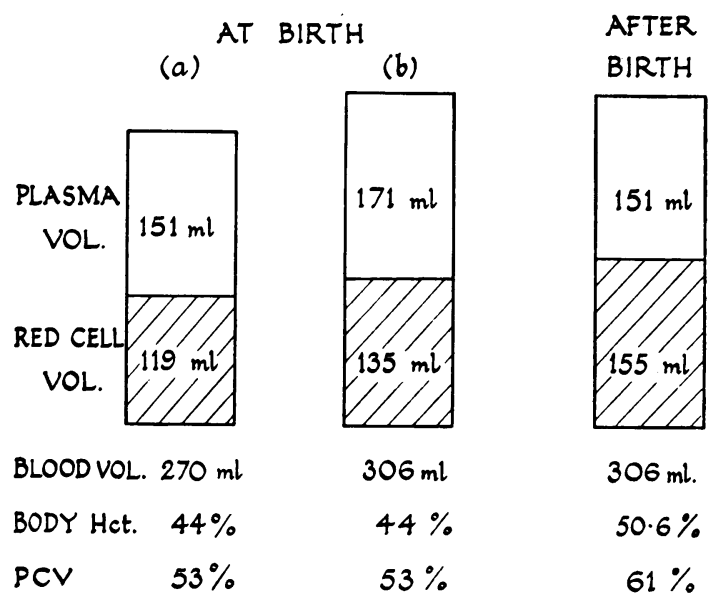

FIG. 4.-Calculated changes in red cell volume after birth, to account for an observed change in PCV from $53 \%$ at birth to $61 \%$ after birth: (a) assuming plasma volume unchanged, (b) assuming blood volume unchanged.

It will be seen that the calculated gain in red cell volume after birth is either (a) $155-119=36 \mathrm{ml}$, which is $23 \%$ of the initial red cell volume, or (b) $155-135=20 \mathrm{ml}$. which is $15 \%$ of the initial red cell volume, depending on which of the two assumptions is made.

This calculation gives an idea of the order of magnitude of the gain in red cell volume, i.e. 20 to $36 \mathrm{ml}$., which would be necessary to account for a postnatal rise of $15 \%$ in PCV such as is observed in a typical infant. With these figures in mind we may proceed to consider three possible sources of red cells which might be added to the circulation after birth. (It should be appreciated that many infants show a much greater postnatal rise in PCV 
than $15 \%$ (see Fig. 3) and would consequently require even larger red cell supplements.)

(a) Red Cells Derived from Transfer of Placental Blood. In the past it has often been observed that the mean $\mathrm{Hb}$ concentration is higher on the first day of life than in cord blood, and where attention has been paid to this difference it has usually been assumed that the postnatal rise in $\mathrm{Hb}$ level is the result of placental blood transfer. This view received weighty support from the work of DeMarsh, Windle and Alt $(1942,1948)$ who compared the $\mathrm{Hb}$ and haematocrit of cord blood with that of blood from the sagittal sinus at a few hours after birth. The latter gave $\mathrm{Hb}$ and haematocrit values on an average some $12-15 \%$ higher, but only if the cord clamping had been delayed, no such difference being seen in infants whose cord had been clamped at once. These authors' findings are thus completely at variance with our own, since throughout our series the cord has been clamped as soon as conveniently possible, yet a significant postnatal rise in $\mathrm{Hb}$ level has been observed in the majority of infants.

We have sought without success to find an explanation for this difference in results. Thus DeMarsh and co-workers took their blood samples from the sagittal sinus, a source we have not used in this series. However, a number of our samples were taken from the internal jugular vein, which, as the direct continuation of the sagittal sinus, is most unlikely to contain blood of different composition. Furthermore, reference to Table 1 shows that in two subjects investigated the $\mathrm{Hb}$ level of sagittal sinus blood was the same as in other veins.

The possibility exists that significant amounts of placental blood might be rapidly transferred to the baby during the terminal stages of delivery. In order to establish the fact that the postnatal rise in $\mathrm{Hb}$ level occurs independently of placental blood transfer, the effect was studied in 17 infants delivered by elective caesarean section, before the onset of labour. In these cases, too, the cord was clamped as soon as possible, so that it seems certain that no appreciable amount of placental blood could have been transferred to the infant. Nevertheless a postnatal rise in $\mathrm{Hb}$ level took place in much the same proportion of these subjects as in those delivered vaginally (Fig. 1), and this rise often exceeded $20 \%$.

We must conclude that the postnatal rise in $\mathrm{Hb}$ level occurs independently of placental blood transfer (although it is, of course, likely to be augmented by any placental blood transfer that is allowed to take place).

(b) Red Cells Derived from Reservoir Sources.
The spleen which weighs only about $10 \mathrm{~g}$. at birth is clearly incapable of providing any significant addition to the red cell volume.

The only other viscus which requires consideration is the liver. This highly vascular organ weighs about $150 \mathrm{~g}$. at birth, but even so it seems hardly conceivable that it could be capable of releasing as much as $20 \mathrm{ml}$. of red cells, or $13 \%$ of its weight.

(c) New Red Cells Derived from HaemoPOIETIC CENTRES. According to Seip (1953) red cells delivered from haemopoietic tissue into the circulation are all reticulated and persist as reticulocytes for about one day. A large addition of new red cells would thus result in a correspondingly large rise in the number of circulating reticulocytes. Therefore, in the present context, where an average rise of the order of $15 \%$ in the red cell volume is being considered, the proportion of reticulocytes would be expected to rise from a normal level at birth of $3-4 \%$, to nearly $20 \%$. It may be said at once that no rise of this magnitude occurs. Wegelius (1948) found a slight transient rise in the reticulocyte level from $2 \cdot 8 \%$ at birth to $3.7 \%$ at two hours. Seip (1955) also found that the level rose slightly, e.g. from $4 \cdot 1 \%$ at birth to $4.5 \%$ after birth, but pointed out that this is what would be expected from the fact that new reticulocytes are added to a smaller volume of blood after elimination of the placental circuit. Our own data (Gairdner et al., 1952) have given similar results, the reticulocytes numbering between $3 \%$ and $4 \%$ both in cord blood and in blood taken during the first day. These results therefore show that red cells from haemopoietic centres cannot be the source of the postnatal rise in haemoglobin level.

Thus we may conclude that addition to the red cell volume does not play a significant part in the haemoglobin rise that we have observed in infants after early clamping of the umbilical cord.

(3) Loss of Plasma Fluid. By exclusion of the other possible mechanisms we must conclude, then, that the postnatal rise in $\mathrm{Hb}$ level must be mainly due to haemoconcentration from a shift of fluid from the vascular compartment.

Two other simultaneous changes support the idea of fluid shift:

(i) A rise in the concentration of plasma protein.

(ii) A rise in the MCHC of the red cells.

The increase in the MCHC implies that there is usually some contraction of the red cells from shift of intracellular fluid into the plasma, at the same time as fluid is extruded from the vascular compartment.

If the blood volume after birth is $\mathrm{v}$, the red cell 
and plasma volumes at birth, and a few hours after birth, can be defined in terms of the $\mathrm{Hb}$ level and the PCV at birth $\left(\mathrm{Hb}_{1}, \mathrm{PCV}_{1}\right)$ and after birth $\left(\mathrm{Hb}_{2}, \mathrm{PCV}_{2}\right)$ as shown in Fig. 5.

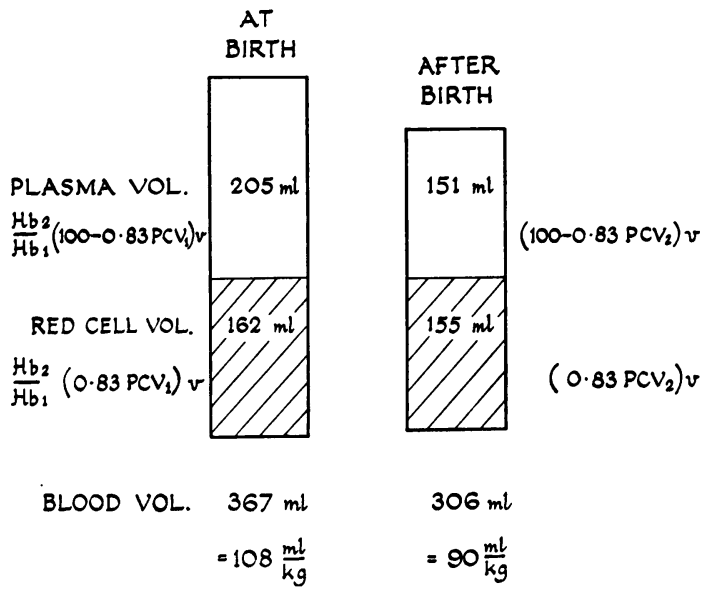

Fig. 5.-Method of calculating red cell and plasma volumes at birth and after birth, in terms of blood volume after birth (v). Numerical values for a typical infant (see text) are shown.

Using this general scheme it is simple to calculate the volume of the plasma fluid shift corresponding to any observed change in $\mathrm{Hb}$ level and PCV. As an example we have taken a typical case of a $3.4 \mathrm{~kg}$. infant where the $\mathrm{Hb}$ after birth rises by $20 \%$ from 16.9 to $20.3 \mathrm{~g}$. $/ 100 \mathrm{ml}$. and the PCV by $15 \%$ from 53 to $61 \%$. The blood volume after birth, corresponding to a PCV of $61 \%$, is $90 \mathrm{ml} . / \mathrm{kg}$. (Mollison et al., 1950), and from this values for the plasma and red cell volumes at birth and after birth have been calculated (Fig. 5).

According to this calculation it will be seen that in a typical case such as that quoted the volume of fluid extruded from the vascular compartment will be $367-306=61 \mathrm{ml}$, while the plasma volume will diminish by $205-151=54 \mathrm{ml}$. The difference between these figures is accounted for by the $7 \mathrm{ml}$. of fluid that has shifted from the red cells, equivalent to a contraction of about $4 \%$ in the red cell volume. The $54 \mathrm{ml}$. of plasma fluid lost from the vascular compartment out of an initial plasma volume of $205 \mathrm{ml}$. represents $26 \%$ of the initial plasma volume.

\section{The Composition of the Fluid Lost from the Vascular Compartment}

Plasma being composed of electrolytes, protein and water, the question next to be answered is whether all these constituents are lost in the same proportions in which they exist in the plasma.

The percentage increase in the concentration of a solute when the volume of a solution diminishes from $V_{1}$ to $V_{2}$ is given by $100 \frac{\left(1 / V_{2}-1 / V_{1}\right)}{1 / V_{1}}$ which reduces to $100\left(\frac{V_{1}}{V_{2}}-1\right)$. If the terms $V_{1}$ and $V_{2}$ are replaced in this expression by the values for the plasma volume at birth and after birth as given in Fig. 5, this expression becomes

$$
100\left(\frac{\mathrm{Hb}_{2}}{\mathrm{Hb}_{1}} \cdot \frac{100-0 \cdot 83 \mathrm{PCV}_{1}}{100-0 \cdot 83 \mathrm{PCV}_{2}}-1\right)
$$

If now the fluid lost from the vascular compartment were protein-free, then the above expression would give the percentage increase in plasma protein concentration in terms of the changes in $\mathrm{Hb}$ level and PCV after birth. If, on the other hand, the fluid lost were whole plasma, there would be no change in the concentration of plasma protein. In Fig. 6 the percentage change in the plasma protein concentration, calculated on the supposition that

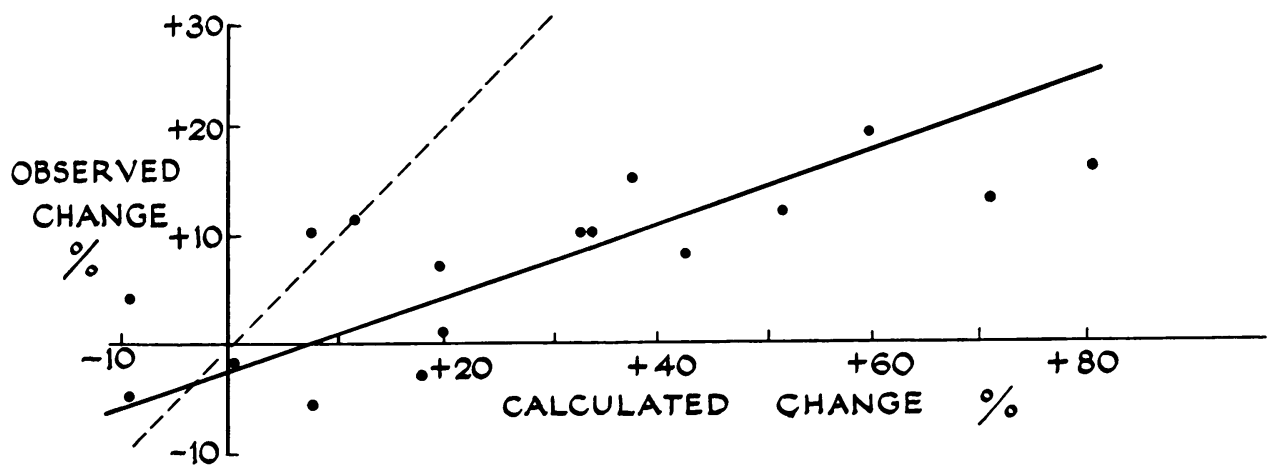

FIG. 6.-Observed change in plasma protein concentration one to eight hours after birth (17 cases), related to change calculated on the supposition that the fluid lost from the vascular compartment after birth is protein-free. Regression (continuous) line shows that observed change is about one quarter as great as calculated change. 
the fluid lost is protein-free, is plotted against the observed change. It will be seen that the points mainly fall far below the broken line representing a 1:1 ratio between the calculated and the observed changes in protein concentration. The position of the regression line shows that the observed change in protein concentration is on the average only about one quarter of the calculated value, and from this fact we may infer that the protein content of the fluid which leaves the vascular compartment is roughly three-quarters that of the plasma.

In the same way, the fact that the plasma sodium shows no postnatal rise implies that any fluid lost from the vascular compartment contains about the same concentration of sodium as does plasma.

In brief, therefore, we may conclude that the fluid lost is largely whole plasma, although the small increase in plasma protein concentration indicates that some additional protein-free fluid also leaves the vascular space.

The Fluid Shift from the Red Cells. We have seen that there is generally a rise in the $\mathrm{MCHC}$ in the first few hours after birth, averaging $4 \cdot 0 \%$. The fact that the MCHC is appreciably higher after birth than at birth is evident also when studying the data provided by other authors who have examined both cord blood and blood taken after birth on Day 1; their results are set out in Table 2. For the four series quoted the average postnatal increase in $\mathrm{MCHC}$ is about $3 \%$.

An increase of $3 \%$ in the MCHC implies a contraction in the volume of the red cell by about the same amount. We have not made direct observations to check whether in individual cases the mean corpuscular volume (MCV) decreases in parallel with the MCHC increase after birth, and in view of the inaccuracy of red cell counts it would be a laborious task to attempt. However, there is some evidence from the literature that the MCV after birth on Day 1 is, on the average, some $3 \%$ lower than at birth (Table 2).
There is thus good evidence that after birth there is a contraction in the volume of the red cells which, on the average, amounts to about $3 \%$. This rapid decrease in volume must be largely caused by a shift of fluid from the cells.

The cause of the fluid shift from the red cells is undecided. Our data show no correlation between the increase in $\mathrm{MCHC}$ and the increase in $\mathrm{Hb}$ level after birth so that, for example, the $\mathrm{MCHC}$ may increase in cases where there is no postnatal $\mathrm{Hb}$ rise. It therefore seems that the shift of fluid from the red cells on the one hand and from the plasma compartment on the other, may prove to be independent effects.

Certainly our data do not suggest that the contraction of the red cells is a response to alteration in the osmotic pressure of the plasma, for the plasma sodium, which (with the chloride) makes the major contribution to the osmotic pressure of the plasma, shows no consistent rise after birth. The small increase noted in plasma protein concentration after birth would have only an insignificant effect on the total osmolarity of the plasma.

It is, however, known (Jacobs and Parpart, 1931) that red cells contract under the following three conditions: a rise in $\mathrm{O}_{2}$ tension; a fall in $\mathrm{CO}_{2}$ tension; or a shift of the $p \mathrm{H}$ towards the alkaline side; and it is possibly a combination of these three effects which causes the haematocrit of arterial blood to be about $1 \%$ lower than that of venous blood (Henderson, 1928; Hope and Verel, 1955). After birth, as soon as air-breathing begins, all three effects operate, the blood $p \mathrm{H}$ (which has the largest effect on red cell size) shifting from $7 \cdot 33$ to $7 \cdot 43$, according to Graham and Wilson (1954). It must be stressed that the gas tensions in a sample of blood examined by ordinary haematological techniques can bear little relation to those in the body. Nevertheless changes in $\mathrm{O}_{2}$ and $\mathrm{CO}_{2}$ tensions provide an attractive theory to explain the postnatal contraction of red cells and this possibility requires further study.

TABLE 2

CHANGE IN COMPOSITION (MCHC) AND SIZE (MCV) OF RED CELLS AFTER BIRTH

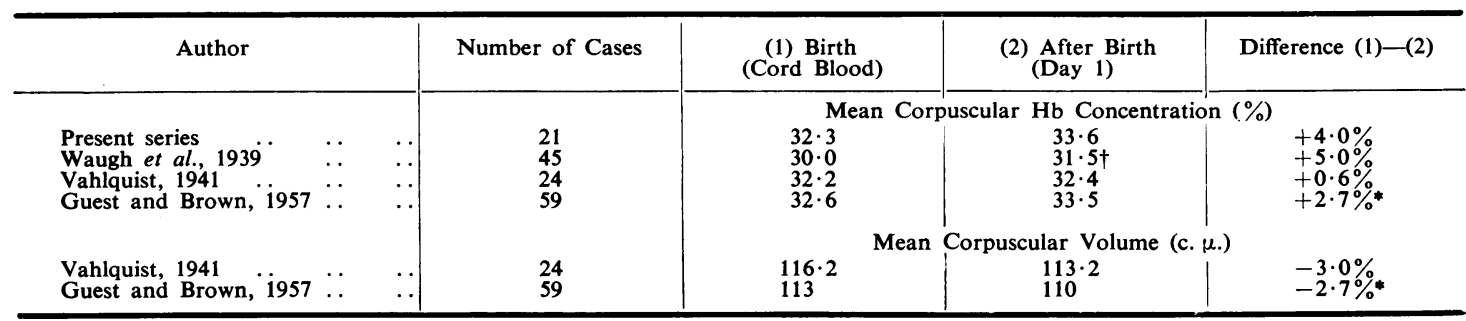

* Differences statistically significant.

† Day 2. 
The Mechanism of the Postnatal Shift of Plasma. We have inferred that in a typical newborn infant birth is quickly followed by the shift of an appreciable fraction of the plasma volume, amounting in an average case to some $54 \mathrm{ml}$. of plasma. At present we can do no more than speculate about the mechanism of this substantial shift of plasma, which often begins within a few minutes of birth and appears to be complete within an hour or two.

From animal and human studies it is known that plasma fluid with varying amounts of protein is continuously flowing out of capillaries. Some of this fluid is reabsorbed on the venous side of the capillary, while the remainder, including practically all the protein, is recovered by the lymphatics and eventually returned to the circulation. It is less well known how considerable is the amount of protein which thus leaves the circulation, giving rise to a regular extravascular circulation of plasma protein via the lymphatic system, the lymph having a concentration of protein of about half that in plasma itself. In the dog it has been estimated that $50-100 \%$ of the total plasma protein leaves the circulation each day (Yoffey and Courtice, 1956).

Under physiological conditions the main variable factor determining the amount of plasma fluid leaving a capillary is the hydrostatic pressure within the vessel. The cause of the postnatal plasma shift may well therefore be sought in the drastically changed haemodynamics of the infant following birth. The re-routing of the blood stream which takes place must presumably lead to a greatly increased blood flow at some sites. At no site is such a change better defined than in the lungs. This subject is discussed by Dawes (1958) who has shown that (in the lamb) birth is followed by (i) a large fall in pulmonary arterial pressure and (ii) a large increase (perhaps threefold) in pulmonary blood flow. The very large decrease in the pulmonary vascular resistance, which these two facts together imply, points to the probability of a large rise in the pressure within the smaller pulmonary vessels. This pressure has not as yet been susceptible to measurement.

It is suggested, then, that the loss of protein-rich fluid takes place from capillaries subjected to an increased pressure following circulatory rearrangements at birth, and that the pulmonary circulation is one site where conditions are such as to favour this.

Blood Volume at Birth. Determinations of the blood volume of the newborn infant have in practice been made when the infant was a few hours old, by which time we must assume from our data that the postnatal change in plasma volume will have already taken place. This conclusion is supported by inspection of the data given by Mollison et al. (1950) in their paper on blood volume in newborn infants, where the (corrected) haematocrit of the normal infants studied is, with a few exceptions, well above the normal mean value of $50 \%$ for cord blood, averaging about $60 \%$. It follows that the blood volume of the infant at birth is appreciably larger than is currently accepted. Referring, for example, to the situation represented in Fig. 5, it will be seen that the inferred blood volume at birth was $108 \mathrm{ml} . / \mathrm{kg}$., compared with $90 \mathrm{ml} . / \mathrm{kg}$. after birth. In this case, therefore, the blood volume at birth was $20 \%$ larger than after birth, $18 \%$ being accounted for by a larger plasma volume, and $2 \%$ by a larger red cell volume.

The Hydraemic State of the Foetus. It is clear therefore that, compared with the infant after birth, the foetus tends to be in a state of hydraemia, i.e. to have a larger plasma volume.*

The question arises as to how far the wide range over which the normal $\mathrm{Hb}$ level in the cord blood varies is partly a function of the degree of hydraemia. In Fig. 7 the postnatal rise in $\mathrm{Hb}$ level has been plotted against the cord $\mathrm{Hb}$ level. The regression line is shown and this is highly significant $(r=0 \cdot 352$, $\mathrm{p}=<0.01$ ). It can be seen that there is a tendency for the largest postnatal rises in $\mathrm{Hb}$ level to occur amongst those infants that have a low initial level.

This is an interesting finding, because it throws some light on a fact which has puzzled us, the remarkably wide range of the normal cord $\mathrm{Hb}$ level, the $95 \%$ range being $13 \cdot 7-20 \cdot 1 \mathrm{~g}$. (Marks et al., $1955)$, with occasional values observed as low as $10.4 \mathrm{~g}$. and as high as $22.0 \mathrm{~g}$. The findings shown in Fig. 7 strongly suggest that the lower $\mathrm{Hb}$ values are the result of haemodilution. For instance, while 18 out of 92 infants were born with a cord $\mathrm{Hb}$ below $15 \mathrm{~g}$., a few hours after birth only two infants showed so low a level.

As we have inferred that immediately after birth the plasma volume may decrease appreciably, it is of interest that there is some evidence of a similar lability of the plasma volume in the foetus before birth. Born, Dawes and Mott (1956) observed that in the foetal lamb subjected to hypoxia, as by decreasing the oxygen content of the air inspired by the ewe, there was a rise averaging $11 \%$ in the oxygen capacity (i.e. the $\mathrm{Hb}$ concentration) of the foetal blood, the oxygen capacity tending to return

\footnotetext{
* In contrast to this use of the term hydraemia in its strict sense, the term has sometimes been loosely applied to the foetus, and equally to the newborn infant, in the sense that the water and salt content of the body is high (Gans and Thompson, 1957).
} 


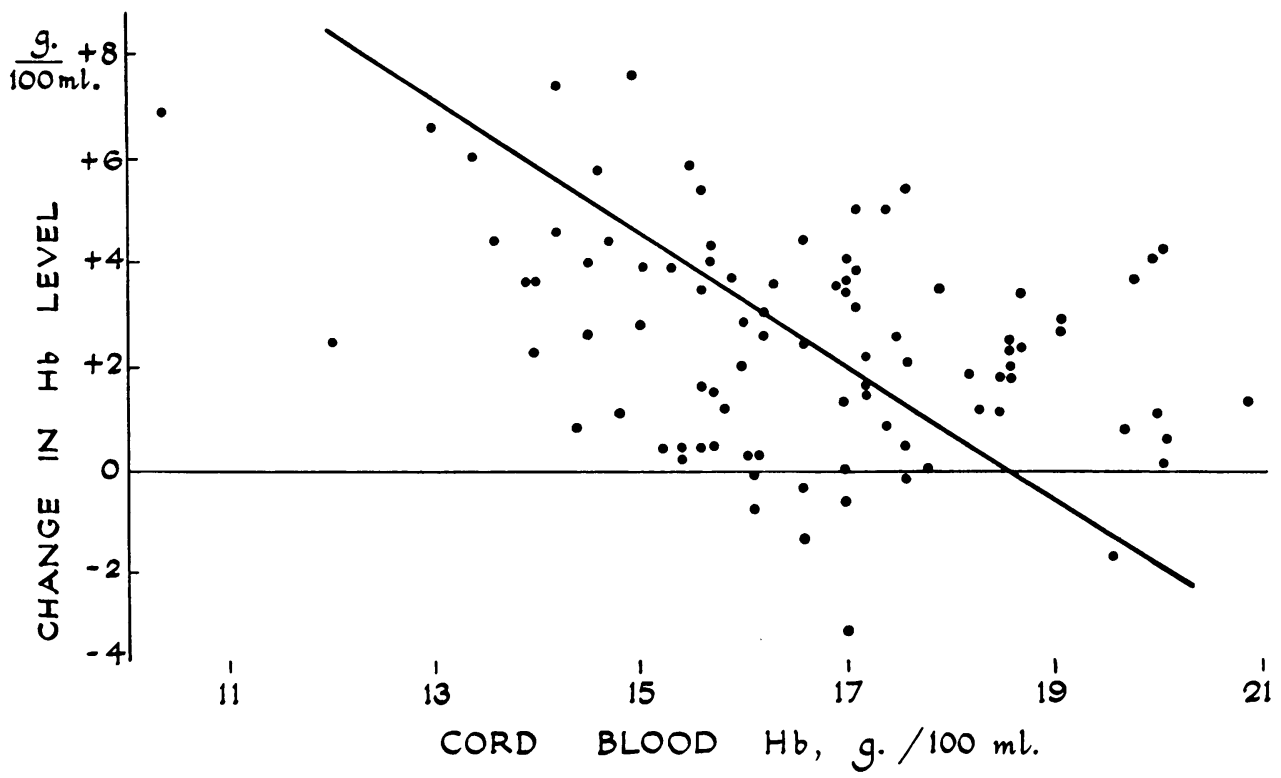

Fig. 7.-Change in $\mathrm{Hb}$ level one to eight hours after birth related to cord blood $\mathrm{Hb}$ level (92 cases). The regression line shows that the lower the cord blood $\mathrm{Hb}$ level, the larger the postnatal haemoconcentration effect.

to its original level after oxygenation was restored. This effect was shown not to be due to placental blood transfer and would be most readily explained on the basis of the readiness of the foetus to lose plasma from the circulation. The same explanation may account for the observation of Cook, Brodie and Allen (1957) that the mean cord blood $\mathrm{Hb}$ level of infants born with evidence of pre-natal hypoxia (meconium staining of nails, skin and cord) was 19.2 g. $/ 100 \mathrm{ml}$., significantly higher than the level of $17 \mathrm{~g}$. in normal infants, and attributed by these authors to haemoconcentration. A similar conclusion was reached by Sjöstedt, Engelson and Rooth (1958) who found that infants showing meconium staining of the skin tended to have an abnormally low oxygen saturation of umbilical vein blood, and an abnormally high mean $\mathrm{Hb}$ level, $17 \cdot 0 \mathrm{~g}$. against the normal $16 \cdot 1$.

The Premature Infant and Plasma Shift. Only a few of the infants studied in this series were premature. In these few the usual tendency for the $\mathrm{Hb}$ level to rise strikingly after birth has been observed and it seems likely that in premature as in normal infants, birth is often followed by a shift of plasma from the circulation. A fluid shift which is evidently a physiological process in the normal infant might, however, prove an important handicap to an immature infant. The conspicuous tendency for the premature infant to develop generalized subcutaneous oedema within a few hours of birth comes to mind in this connexion, since it implies that immediately after birth there is a substantial shift of fluid from an undetermined source into the interstitial spaces. Moreover, there is some evidence to suggest that this fluid has a high content of protein, since Baar (1956) has been able at necropsy to collect oedema fluid from the leg in some premature infants. He found the protein content of this fluid to be near to that of plasma, with a concentration of from 3 to $7 \mathrm{~g}$. \%, and an electrophoretic pattern similar to that of plasma, save that the proportion of albumen was rather higher.

More important from the point of view of the vital functions is the part played by oedema in the pulmonary failure which is the main cause of death in the premature. From the standpoint of morbid anatomy there are two facets to these cases: resorption atelectasis, and intra-alveolar 'hyaline membrane'. The latter is only seen in infants that have survived several hours (Potter, 1952) and is probably formed from a transudate of plasma protein. We have already given reasons why the lungs are likely to be one of the sites where plasma is extruded postnatally. It is suggested that in the premature infant the normal mechanism by which the lymphatic system recovers protein leaving the circulation is overwhelmed, and that pulmonary oedema follows, with some of the protein-rich oedema fluid exuding into the alveolar space. In the average infant at 
birth the lungs weigh about $60 \mathrm{~g}$., compared with a volume of fluid entering the extravascular space which we have estimated in a typical case to amount to about $61 \mathrm{ml}$. Thus even a small part of this fluid, if it remained in the lungs, might be of functional significance in the immature infant.

This reasoning leads then to the view that pulmonary oedema may be the primary disturbance in the pulmonary failure which so often overtakes the premature baby within a few hours of birth, and that one factor in the pathogenesis of the oedema may be the postnatal shift of plasma from the circulation.

\section{Summary}

Immediately after birth there is a rise in concentration of $\mathrm{Hb}$ and in $\mathrm{PCV}$ in the majority of infants. The rise may be discernible within a few minutes of birth and is probably completed within an hour or two. It occurs in the absence of any transfer of placental blood.

The possible causes are considered in detail and it is concluded that the effect is brought about by a shift of fluid from the vascular compartment.

This fluid is mainly whole plasma, and its volume may amount to a large fraction of the circulating plasma at birth, a quarter or more.

In addition, there is a shift of fluid from the red cells, the volume of red cells contracting after birth by an average of $3 \%$.

The cause of these fluid shifts is discussed and it is suggested that the plasma loss may be a consequence of the re-routing of the circulation after birth.
These results imply that the foetus in utero is hydraemic, i.e. has a large plasma volume.

Haemodilution is thus in part responsible for the wide range of the normal cord $\mathrm{Hb}$ level.

Possible clinical implications are mentioned, particularly in relation to the pulmonary failure of the premature infant.

We gratefully acknowledge biochemical help given us by Professor R. A. McCance, F.R.S., Dr. R. S. Lawrie and Mr. S. H. H. Davison, and haematological facilities granted us by Dr. D. G. Chalmers.

\section{REFERENCES}

Baar, H. S. (1956). Quoted by Crosse, V. M. (1957). Ann. paediat.

Born, Genn., 3, 153 .

Chaplin, H. and Mollison, P. L. (1952). Blood, 7, 1227.

- 1 and Vetter, H. (1953). J. clin. Invest., 32, 1309

Cook, C. D., Brodie, H. R. and Allen, D. W. (1957). Pediatrics, 20, 272.

Dawes, G. S. (1958). In Recent Advances in Paediatrics, ed. D. Gairdner, 2nd ed. Churchill, London.

DeMarsh, Q. B., Windle, W. F. and Alt, H. L. (1952). Amer. J. Dis. Child., 63, 1123 .

- Alt, H. L. and Windle, W. F. (1948). Ibid., 75, 860.

Gairdner, D., Marks, J. and Roscoe, J. D. (1952). Arch. Dis. Childh., $27,214$.

Gans, B. and Thompson, J. C. (1957) Proc, roy, Soc. Med, 50, 929. Gis. Child., 87, 287.

Henderson, L. J. (1928). Blood, a Study in General Physiology, chap. 7. Yale University Press, New Haven.

Hope, A. and Verel, D. (1955). Clin. Sci., 14, 501.

Marks, J., Gairdner, D. and Roscoe, J. D. (1955). Arch. Dis. Childh., 30, 117.

Mollison, P. L., Veall, N. and Cutbush, M. (1950). Ibid., 25, 242.

Potter, E. L. (1952). Pathology of the Fetus and the Newborn. Year Book Publishers, Chicago.

Seip, M. (1953). Acta med. scand., Suppl. 282.

(1955). Acta paediat., 44, 355.

Sjöstedt, S., Engelson, G. and Rooth, G. (1958). Arch. Dis. Childh.,

58, 123.
Wegelius, R. (1948). Acta paediat., 35. Suppl. 4.

Wegelius, R. (1948). Acta paediat., 35. Suppl. 4.
Yoffey, J. M. and Courtice, F. C. (1956). Lymphatics Lymph and Lymphoid Tissue, 2 nd ed., chap. 2 . Arnold, London. 